Wigham, C.R. \& Chanier, T. (in print). Interactions between text chat and audio modalities for L2 communication and feedback in the synthetic world Second Life. Computer Assisted Language Learning (CALL Journal).

\title{
Interactions between text chat and audio modalities for L2 communication and feedback in the synthetic world Second
}

Life.

\begin{abstract}
This paper reports on a study of the interactions between text chat and audio modalities in L2 interaction in a synthetic (virtual) world and observes whether the text chat modality was used for corrective feedback and the characteristics of the latter. This is examined within the context of a hybrid Content and Language Integrated Learning design workshop. This course involved 17 students of architecture whose L2 was either French or English and for which the synthetic world environment Second Life was employed for distance language sessions. Using multimodal transcriptions of the interaction data from these sessions, it was found that text chat was employed for content-based interaction concerning the task as well as feedback concerning non-target-like errors in the audio modality. Feedback predominantly concerned lexical errors and was offered in the form of recasts. The multimodality of the environment did not appear to cognitively overload students who frequently responded in the audio modality to corrective feedback offered in the text chat. The study highlights the need to train language tutors who wish to exploit synthetic worlds to use the text chat in parallel with the audio to support learners' verbal production with respect to verbal participation and proficiency.
\end{abstract}

Keywords: synthetic worlds, multimodality, text chat, feedback, content and language integrated learning (CLIL)

\section{Introduction}

Three-dimensional synthetic (virtual) worlds are highly multimodal environments which introduce possibilities for nonverbal communication and include, in the verbal $^{1}$ mode, both audio and text chat modalities. This study, firstly, addresses the usage and role of the text chat in language learning sessions held in a synthetic world, in view of the fact that the modality is in competition with a range of other communication modalities. Secondly, it explores whether the text chat can serve for language feedback provision.

\section{Synchronous text chat}

\footnotetext{
1 Throughout the text, we use the adjective 'verbal' as an antonym of 'nonverbal'. Hence it refers to a very general usage in linguistics that means 'verbal' objects belong to language and linguistics study. Our usage does not imply that the text chat modality has an "oral" or "aural" nature, or that it can directly be assimilated to speech, as clearly explained by Freiermuth (2011) in his study of the linguistic choices made by political adversaries in online text chat.
} 
A growing body of research examines synchronous computer-mediated tools and the application of these in language learning contexts. Synchronous text chat describes types of technologies that allow users to transfer text messages between computers quasi instantaneously. Several studies suggest these messages bear characteristics that resemble spoken rather than written language (Chun, 1994; Lamy \& Hampel, 2007,). However, as Beißwenger et al., (2012) underline, one characteristic of synchronous text chat is that each message is posted as a block. Therefore, revisions to the message that are apparent to the other interlocutors cannot be made partway through the construction of the message. The structure of the discourse, thus, differs to that of spoken interaction (Payne \& Whitney, 2002).

Concerning L2 learning, it is suggested that text chat may help increase students' verbal participation due to interaction being less teacher-centred than in face-to-face environments and involving a higher frequency of student-tostudent exchanges (Chun, 1994; Kern, 1995; Ortega, 1997). This is attributed to the egalitarian nature of the turn-taking rules (Kelm, 1992) and the possibility for 'conversation doubling' whereby a variety of micro-conversations co-exist during the same discussion because participants can respond differently to the same utterance. This multiplication of the initial topic of discussion leads to interaction patterns perceived as enriching exchanges for L2 learners (Yun, 2009).

However, one risk is that the complexity of interwoven conversation threads may lead to communication breakdown (Bower \& Kawaguchi, 2011; Werry, 1996). Text chat also allows students to overcome hesitance as the modality is perceived as 'face-saving' (Hoffman, 1996) relieving students of their inhibitions and allowing free expression (Chun, 1994; Freiermuth, 2001;Warschauer, 1996) and, thus, enhancing students' willingness to communicate (Freiermuth \& Jarrell, 2006).

Whilst the majority of studies into synchronous text chat have focused specifically on environments in which the text chat is the only verbal communication modality, developments in computer-technology mean that online communication environments are becoming increasingly multimodal (Stockwell, 2007), often combining in the verbal mode a text chat modality and an audio modality. This paper, thus, examines text chat within a multimodal environment, and specifically the interactions between text chat and audio modalities for L2 communication and feedback.

\section{Text chat in multimodal environments}

Ciekanski \& Chanier (2008) propose a classification of multimodal environments; including those which offer text chat and voice chat and those they term 'audio-graphic conferencing environments'. In both types of environments, studies into L1 and L2 communication have often suggested that the text chat acts only in adjunct to the voice chat. For example, when there are technical problems, in the opening and closing of sessions or for off-task asides addressed to peers (Cosnier \& Develotte, 2011; Cunningham, Fägersten \& Holmsten, 2010; Liddicoat, 2011; Palomeque, 2011). Often tutors and researchers suggest an anxiety concerning overloading learners, particularly of lower levels, if several modalities are used. Hampel cautions, for example, that tasks "have to take into account the fact that students may be overwhelmed by the resources [modalities] that are on offer" (2006:119). However, in an audio- 
graphic conferencing environment which included iconic and whiteboard tools, Vetter \& Chanier (2006) show that, although for language learning the audio modality will take precedence, the text chat and other modalities (e.g. nonverbal) work in support of the audio. In their study of an English-as-aforeign-language course, they observed that the false beginners group ${ }^{2}$ communicated more than twice as much in the text chat than in the voice chat and that the average number of words per turn in the text chat was higher than the average for the more advanced learners' group. Certain learners showed a preference for using the text chat, and the verbal modalities exemplified the phenomenon of participation equalisation between the voice chat and text chat. Hampel \& Stickler's (2012) study of a German-as-a-foreign-language course held in an audio-graphic conferencing environment similarly showed that students had preferences for contributing either in the audio or in the text chat modality. They also observed that, whilst the tutors were the dominant participant in both the text chat and voice chat, that they, unlike the students, contributed proportional numbers of acts in both modalities. Due to the environment under investigation being half-duplex (only allowing one person to speak at a time - other users must queue to use the voice chat) the text chat played a real role in the L2 interaction, being used by students to agree with, challenge or question the main audio discussion and by tutors to respond to students' spoken contributions and recast or model language from the audio productions.

To the list of multimodal environments proposed by Ciekanski \& Chanier (2008), Deutschmann, Panichi \& Molka-Danielson (2009) highlight synthetic (virtual)

worlds as a fourth type of synchronous CMC tool. Synthetic worlds are highly multimodal in nature, combining in the verbal mode voice chat and text chat and, in the nonverbal mode, several different communication modalities including avatar movement, kinesics, proxemics and appearance (Peterson, 2006; Wigham \& Chanier, 2013).

Concerning L2 learning, synthetic worlds may reduce apprehension and embarrassment (Sanchez, 1996; Schweinhorst, 2002; Wehner, Gump \& Downey, 2011) about expressing oneself in the target language. Peterson (2010) suggests that the perceived beneficial aspects of interaction in synthetic worlds are reinforced by the presence of avatars that allow learners to take risks while feeling safe to practise language (Teoh, 2007) and that are perceived by learners as helping them initiate conversations with other synthetic world users (Jauregi et al., 2011).

It is suggested that the multimodal nature of synthetic worlds allows for richer and more effective collaborative learning than in two-dimensional online environments (Dalgarno \& Lee, 2009) and provides an authentic environment for communication (Liou, 2012). However, some studies have suggested that the multimodal nature of synthetic world environments may overload learners. For example, Toyoda and Harrison (2002), in a study of negotiation of meaning

\footnotetext{
${ }^{2}$ These students' previous study of English dated back to between five and thirty years prior to the course.
} 
between non-native and native Japanese speakers, report on the use of the nonverbal mode alongside the text chat modality ${ }^{3}$. They describe that although the participants changed the appearance of their avatars they made little use of avatar movement. Toyoda and Harrison suggest that when the participants were interacting in the text chat, they did not have any 'spare time' to attempt to use their avatars' movement features. As Deutschmann, Panichi \& Molka-Danielson (2009) advise, there is much to be done regarding the multimodal nature of synthetic worlds before the potential benefits of the environment can be evaluated regarding language learning. Concerning the verbal mode for example, we can question whether there is the place for text chat to play a role in the communication, as observed in audio-graphic conferencing environments or, whether the text chat will act only in adjunct to the voice chat, considering it is equally in competition with several nonverbal modalities. Other queries are the stance tutors adopt vis à vis the text chat: whether they accord importance to this modality, amongst the others (audio, proxemics, kinesics, production), or not, and the role that the text chat plays in terms of discourse functions. These questions serve as a basis for this study.

\section{Text chat and feedback}

One of the affordances of text chat in monomodal environments is that it portrays some of the same language benefits for Second Language Acquisition as face-to-face interaction. These include self-repair (Kitade, 2000) facilitated by the communication's textual nature which helps learners to notice the gaps and by the tools which allow learners to scroll back to monitor their language production. Research into NS-NNS exchanges in text chat has also examined feedback offered to learners. Bower \& Kawaguchi (2012) detail the forms this feedback might take, distinguishing between corrective feedback (either explicit or implicit corrective responses to non-target-like language) and negotiation strategies which draw learner attention to non-target-like language without providing the correct form. Four types of implicit corrective feedback form the latter category: clarification requests, repetition, confirmation and comprehension checks.

Studies into monomodal text chat environments show varying results concerning the percentage of NS responses to non-target-like language which provide corrective feedback in text chat exchanges and the percentage of nontarget-like turns which received corrective feedback and which then lead to modified output on the part of the NNS (Table 1).

\begin{tabular}{|l|l|l|l|}
\hline $\begin{array}{l}\text { Authors and date of } \\
\text { study }\end{array}$ & L2 & $\begin{array}{l}\text { Percentage of NS } \\
\text { responses to NNS } \\
\text { which included } \\
\text { corrective feedback }\end{array}$ & $\begin{array}{l}\text { Percentage of non- } \\
\text { target-like turns } \\
\text { receiving } \\
\text { corrective } \\
\text { feedback which led } \\
\text { to modified output }\end{array}$ \\
\hline Iwasaki \& Oliver (2003) & Japanese & $22 \%$ & Over 25\% \\
\hline Morris (2005) & Spanish & $56 \%$ & $60 \%$ \\
\hline
\end{tabular}

\footnotetext{
${ }^{3}$ NB. At the time of the study, the synthetic world used Jewels included only the text chat modality in the verbal mode and no audio modality.
} 


\begin{tabular}{|l|l|l|l|}
\hline Lee (2006) & Spanish & $73.2 \%$ & $50 \%$ \\
\hline Sotillo (2005) & English & $33 \%$ & $37 \%$ \\
\hline $\begin{array}{l}\text { Bower \& Kawaguchi } \\
(2012)\end{array}$ & English & $0.8 \%$ & - \\
\cline { 2 - 4 } & Japanese & $4.1 \%$ & - \\
\hline
\end{tabular}

Table 1. Results of previous studies into corrective feedback provision in text chat

Concerning the focus on negotiation strategies in text chat interactions, studies by Blake (2000), Pellettieri (2003) and Tudini (2003) found that lexical nontarget-like language prompted more negotiation than grammatical non-targetlike language. O'Rourke (2005) also suggests that the more common focus of negotiation of meaning is on overall meaning rather than language form or structure. In contrast, in Tudini's later study (2007), negotiation sequences triggered by lexical and grammatical issues are more balanced. However, Tudini demonstrates that whilst the NNS were more likely to negotiate lexis rather than grammar, the NSs intervened more frequently concerning grammatical nontarget-like language than on students' use of non-target-like vocabulary. These studies inform several of the research questions developed for this current study.

\section{Research questions}

In this study, the following research questions are posed:

- What role does text chat play in the interaction? Specifically, what discourse functions do text chat acts hold?

- Can text chat serve for feedback provision and in this multimodal environment, can students pay attention to feedback provision?

- What type of errors lead to feedback in the text chat and what strategies are used to provide feedback?

- Given the multimodal nature of the synthetic world, will students, having to deal with multiple communication channels, be able to respond to feedback in the text chat? When, and in what modality, will responses occur?

\section{Context of study}

This section presents the learning design of our study and the participants involved.

\section{Learning design}

The context for the study was a five-day intensive Content and Language Integrated Learning (CLIL) design "studio" entitled 'Building Fragile Spaces'4. The studio / workshop process is a typical architecture learning approach that

\footnotetext{
${ }^{4}$ The workshop formed an action with the European project 'Architectural and Design based Education and Practice through Content and Language Integrated Learning using Immersive Virtual Environments for 21st Century Skills', Lifelong Learning Programme, KA2 Languages. The pedagogical scenario for Building Fragile Spaces was designed by architecture teachers from the Ecole Nationale Supérieure d'Architecture Paris-Malaquais (ENSAPM) and language teachers from Université Blaise Pascal.
} 
focuses on hands-on, collaborative, learning. It is also used in other fields (see Perkins, 2010), and typically employed during intensive courses organised around project-based assignments for which students are expected to integrate skills learnt in other courses (Do \& Gross, 1998).

The overall course objective of Building Fragile Spaces was for the architecture students to collaboratively create, in small workgroups, an architectural model in Second Life which responded to a thematic design brief ${ }^{5}$. Their working language was their L2 (French or English).

Further to the suggested advantages of synthetic worlds for $\mathrm{L} 2$ learning discussed in Section 1, the benefits of synthetic worlds as shared spaces advantageous for fostering the co-existence of generative, analytic and criticalthinking skills which are essential in the teaching of architecture (Garner et al., 2011) prompted the choice of learning environment for a CLIL course and influenced the architecture tutors' formulation of the design briefs.

To assist the students in their interaction and collaboration, language tutors accompanied students remotely during sessions in Second Life (Figure 1). These included introductory sessions to Second Life, introductory building sessions and group reflective sessions (detailed in Rodrigues et al., in press). This study focuses on the latter sessions.

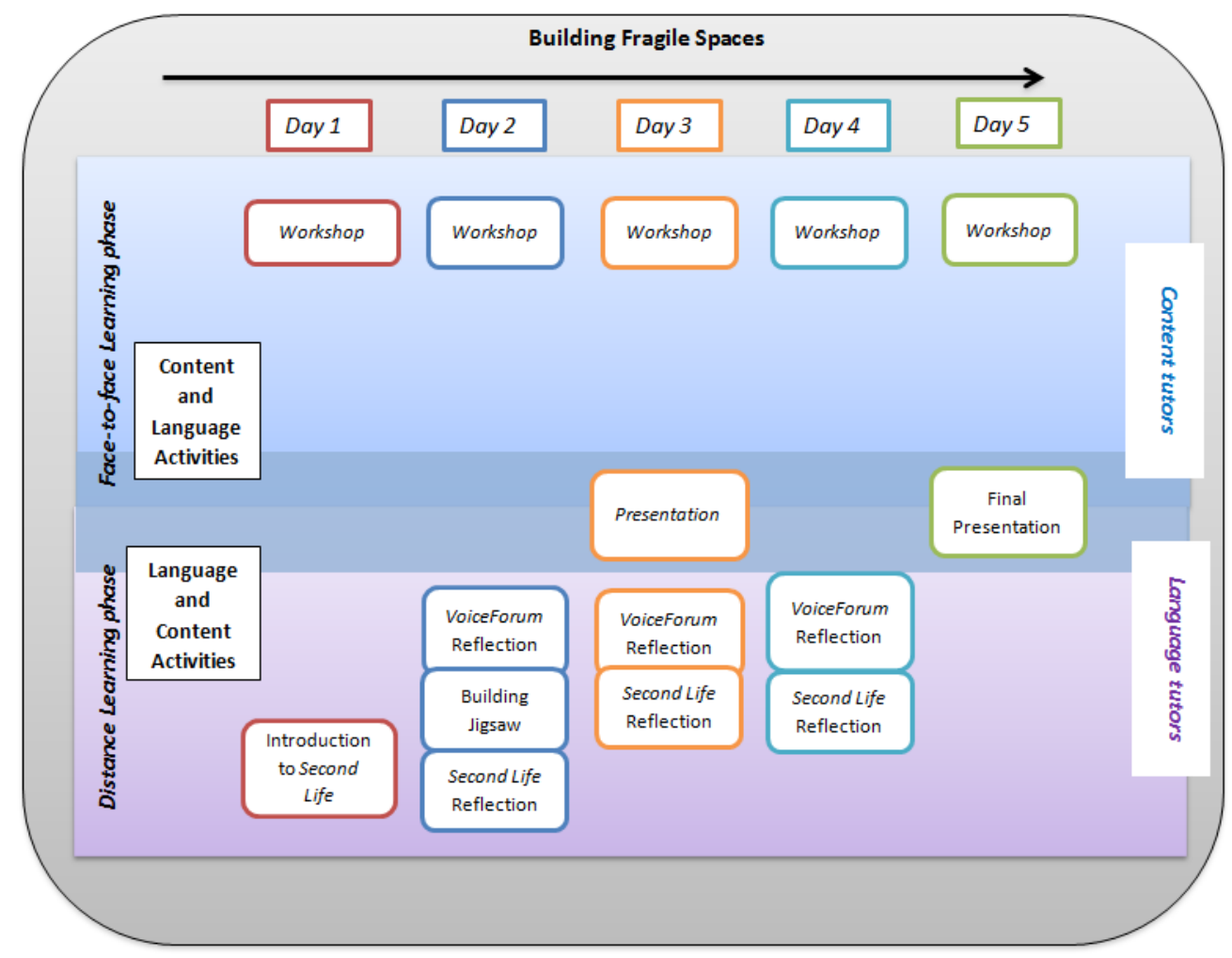

Figure 1: Learning design of the Building Fragile Spaces course (from Rodrigues, et al., in print)

The primary objective of the reflective sessions was not linguistic, but for students, firstly, to articulate and deepen their understanding of their

\footnotetext{
${ }^{5}$ For example, one of the workgroups was given the theme of 'Land+scapes'. Their brief was 'Consider how to develop the spatial archetypes and architectural models for building a sustainable, singular educational metaverse. Think about the aspects of foundation, partition and envelope in your answer to the design brief.'
} 
workgroup's workshop process and, secondly, to be able to distinguish the pertinent information in terms of their workgroup's overall design brief. Students were asked to bring to the sessions images of their inworld work and notes taken during the day reflecting their feelings concerning their workgroup's progress on the project. During the 45-minute sessions, the students interacted in their L2. They were asked, firstly, to explain their individual contribution to the advancement of the group's model and, secondly, to recall and describe the feedback given to them by their architecture teachers during the face-to-face sessions, to infer the relevance of this, and identify possible paths of future enquiry / direction for their group work.

\section{Participants and groups}

The course involved eight female and nine male architecture students, aged between 21 and 25 . Their study year ranged from first-year undergraduates to second-year Master's students. French was the mother tongue of nine of the students. The mother tongues of the remaining students were Spanish, Chinese, Italian, Korean and Arabic. Two students were bilingual. One student Jessieboo had both French and English as her mother tongues and another student Wuhuasha had Chinese and Hō-ló-ōe, a dialect of Chinese, as his mother tongues. The students had studied their L2 for an average of 10 years within the context of an educational institution. The EFL students' English was of B1-B2 ${ }^{6}$ CEFR level (Council of Europe, 2003) the French-as-a-foreign-language (FFL) students $\mathrm{A} 2-\mathrm{B} 1{ }^{7}$. Eleven students had experience of using their $\mathrm{L} 2$ to communicate with native speakers. The FFL students were foreign exchange students at the architecture school.

Concerning the students' distance communication profiles, 12 students had experience of text chat tools and eight students used these on a daily basis. Twelve students had experience of audio/video conferencing tools. Only one student had previously participated in a distance learning course. Two students had previously used Second Life as part of an earlier architecture studio course. This course, however, had not included any language components.

The students selected the CLIL course from a choice of intensive optional modules which ran in parallel at the architecture school during February 2011. During the course, they were divided into four workgroups. This division was thematic and linguistic. Each workgroup received a different architectural brief and had a dominant second language (see Table 2).

\footnotetext{
${ }^{6}$ At a B2 CEFR level, a language learner can "understand the main ideas of a complex text on both concrete and abstract topics, including technical discussions in his field of specialization" and can interact with a degree of fluency and spontaneity that makes regular interaction with native speakers quite possible without strain for either party" (Pearson Longman, nd:5).

${ }^{7}$ At an A2 CEFR level, the learner can understand interaction related to areas of most immediate relevance (personal information, local geography, employment) and can communicate in simple and routine tasks requiring simple and direct exchange of information. At a B1 level, the learner is considered a more independent user of the language. He can understand "the main points of clear standard input on familiar matters regularly encountered in work, school, leisure" and can "deal with most situations likely to arise when travelling in an area where the language is spoken" (Pearson Longman, nd:5).
} 


\begin{tabular}{|l|l|l|l|}
\hline Workgroup & $\begin{array}{l}\text { Target } \\
\text { language }\end{array}$ & L2 level (CEFR) & $\begin{array}{l}\text { Student participants } \\
\text { (participants' codes) }\end{array}$ \\
\hline avatars (AV) & French (FFL) & A2-B1 & $\begin{array}{l}\text { Emmegi88, Prevally, } \\
\text { Crispis, Pjgamez }\end{array}$ \\
\hline $\begin{array}{l}\text { land+scapes } \\
\text { (LS) }\end{array}$ & French (FFL) & A2-B1 & $\begin{array}{l}\text { Antoniobri, Zeinarez, } \\
\text { Wuhuasha, } \\
\text { Hyungyoonrez } \\
\text { Yingrez610 }\end{array}$ \\
\hline (e)spaces (ES) & English (EFL) & B1-B2 & $\begin{array}{l}\text { Tingrabu, Hallorann, } \\
\text { Quentinrez, Romeorez }\end{array}$ \\
\hline scenario (SC) & English (EFL) & B1-B2 & $\begin{array}{l}\text { Jessieboo, Audreyrez, } \\
\text { Arnaudrez, Nathanrez }\end{array}$ \\
\hline
\end{tabular}

Table 2. Workgroup information

Two architecture teachers accompanied the workgroups in the face-to-face environment. One tutor was a native English speaker the other a native French speaker. A FFL tutor (Tfrez1) and an EFL tutor (Tfrez2) accompanied the students during distance language sessions in the synthetic world.

\section{Research methodology}

Building upon our previous work to understand multimodal communication structures (Vetter \& Chanier, 2006; Ciekanski \& Chanier, 2008), we devised a methodological framework for multimodal transcription of synthetic world sessions (Wigham \& Chanier, 2013). This methodology involves data collection from screen and audio output as well as text chat logs and is based on a classification of communication modalities in the synthetic world Second Life (see Table 3). Transcriptions gave us access to the measurable variables of number and length of acts (per participant and per session) and floor space in each modality. We consider floor space as the sum of the total number of all acts within a specific modality for an individual with reference to the total number of all acts communicated in this modality by all participants present. 


\begin{tabular}{|c|c|c|c|}
\hline $\begin{array}{c}\text { Communicatio } \\
\text { n mode }\end{array}$ & $\begin{array}{c}\text { Communicatio } \\
\text { n modality }\end{array}$ & $\begin{array}{l}\text { Act type and } \\
\text { transcription } \\
\text { code }\end{array}$ & Explanation \\
\hline \multirow{3}{*}{ verbal } & \multirow{2}{*}{$\begin{array}{l}\text { audio (voice } \\
\text { chat) }\end{array}$} & audio act (aud) & $\begin{array}{l}\text { verbal act in the full } \\
\text { duplex public audio } \\
\text { channel }\end{array}$ \\
\hline & & silence (sil) & $\begin{array}{l}\text { interval between two } \\
\text { audio acts greater than } \\
\text { three seconds }\end{array}$ \\
\hline & text chat & text chat act (tc) & $\begin{array}{l}\text { message entered in the } \\
\text { public text chat window }\end{array}$ \\
\hline \multirow{4}{*}{ nonverbal } & \multirow{2}{*}{ proxemics } & movement (mvt) & $\begin{array}{l}\text { avatar movement in the } \\
\text { environment, e.g. avatar } \\
\text { sits down, flies, walks } \\
\text { backwards }\end{array}$ \\
\hline & & $\begin{array}{l}\text { entrance into / } \\
\text { exit from the } \\
\text { environment } \\
\text { (eex) }\end{array}$ & $\begin{array}{l}\text { avatar enters or exits the } \\
\text { synthetic world }\end{array}$ \\
\hline & kinesics & kinesic (kin) & $\begin{array}{l}\text { avatar gestures and } \\
\text { movements made by an } \\
\text { avatar's body part e.g. } \\
\text { nod, point, clap }\end{array}$ \\
\hline & production & production (prod) & $\begin{array}{l}\text { production or display of an } \\
\text { object in the Second Life } \\
\text { environment }\end{array}$ \\
\hline
\end{tabular}

Table 3. Classification of communication acts in Second Life

Although our data include transcription of nonverbal interaction, this study concentrates on the two verbal modalities: voice and text chat.

\section{Data annotation with reference to our research questions}

The transcription software used allowed us to export the multimodal transcriptions in XML format. This facilitated data annotation regarding our research questions. Our data were annotated in XML at three levels (Figure 2). Firstly, to address the role of the text chat, at the act level we coded each text chat act depending on its discourse function. Five categories and codes for discourse function were used: socialisation (soc), technical (tech), conversation management $(\mathrm{cm})$, language form (form) and task (task). 


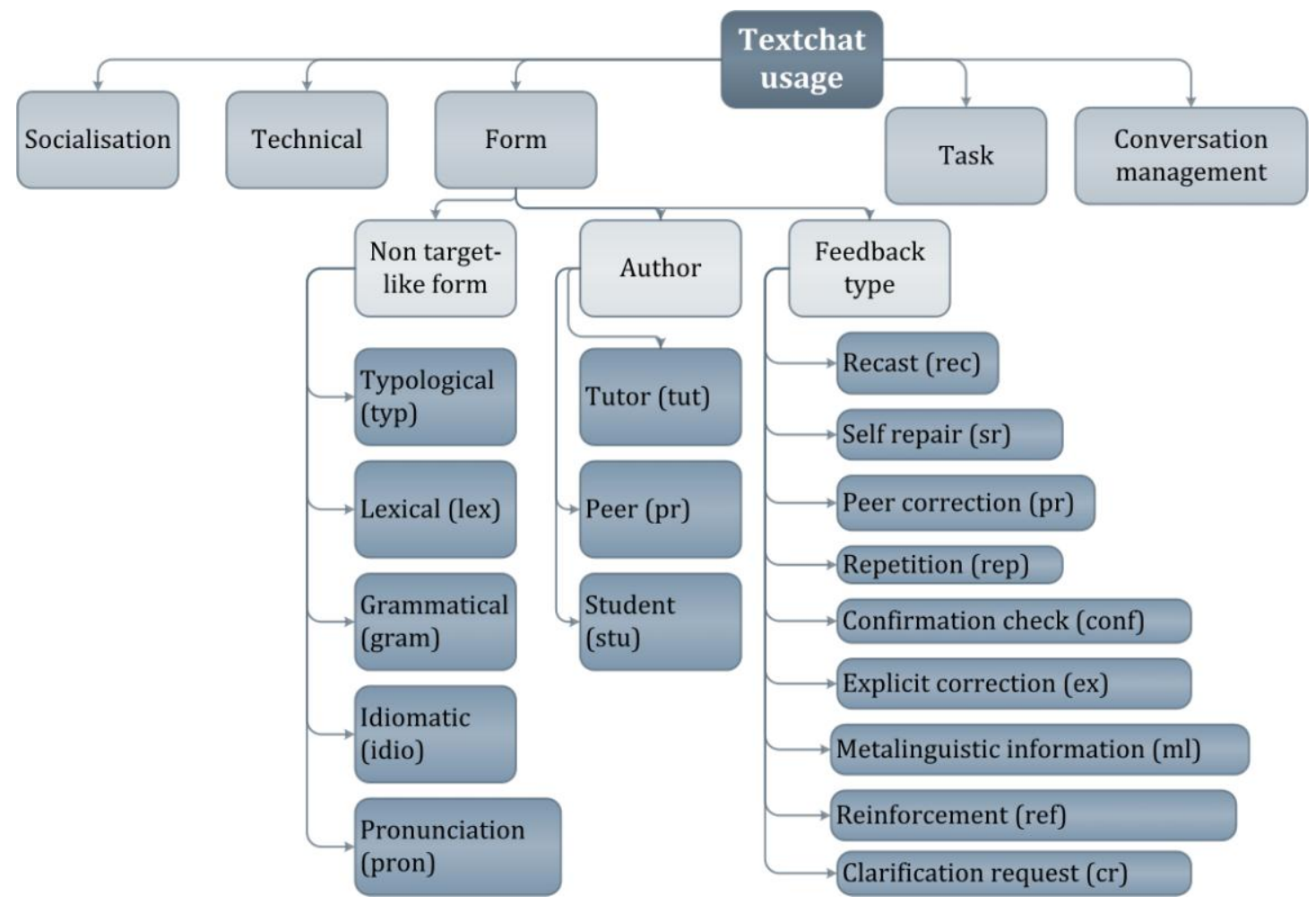

Figure 2. Levels of annotation and codes used

Secondly, for text chat acts which pertained to language form, we coded the specific instances of feedback depending on type of feedback (adapting Bower \& Kawaguchi's categorization, 2011), and the author of the feedback (tutor, student or peer). The non-target-like trigger to which the feedback responded was also coded with reference to type.

Thirdly, to ascertain whether and how students reacted to feedback, four coding categories were utilized:

- 'repetition'- repetition of feedback;

- 'incorporation' - integration of the feedback within an utterance in the target-like form;

- 'non-successful incorporation'- integration of the feedback but in a non-target-like form that needs repair;

- 'acknowledgement' - recognition of the feedback, for example, by thanking the tutor or by using an affirmative reply.

Example 1 illustrates our data annotation methodology. In the audio modality, a participant Arnaudrez, contributes a 26-second audio act. Twelve seconds into this audio act (at 12:53), the tutor Tfrez2, contributes a text chat act to the interaction. The discourse function of this act pertains to form. Indeed, annotation 37 (anno id="37") codes an instance of corrective feedback in the text chat which corresponds to a recast (type="cf-rec") of a grammatical nontarget-like trigger (ntl="gram"). Annotation 36 represents the trigger for this feedback. Annotation 38 corresponds to a repetition by the student of the feedback offered (type="cf-rpt"). 
(1) aud,Arnaudrez [12:31-12:57]: and this is a very personal work so +++ Brad gave some ways to to begin and + then our reflection <anno id="an $36^{\text {" }}>$ lead lead us $</$ anno $>\mathrm{hm}+$ different different ideas <anno id="an38"type="cf-rpt" ref $="$ an $37^{\prime \prime}>$ led us $</$ anno $>$

$$
\begin{aligned}
& \text { tc, }<\text { form }>\text {, Tfrez2 }[\mathbf{1 2 : 5 3 - 1 2 : 5 3 ] : < a n n o ~ i d = " a n ~} 37 \text { " function="form" ntl="gram" } \\
& \text { type="cf-rec" author="tut" ref="an } 36 ">\text { led us }</ \text { anno }>
\end{aligned}
$$

\section{Corpus structuration for data analysis}

The interaction data, alongside the learning design, research protocol and interaction tracks from the Building Fragile Spaces course were structured into an open-access LEarning and TEaching Corpus (LETEC, Reffay, Betbeder \& Chanier, 2012; Chanier \& Wigham, 2011). Interaction tracks from this global corpus were then transcribed and annotated for this study. Data structuration in a machine-readable format rendered our annotation data quantitatively searchable using software that counted XML annotations. Data comparisons were, therefore, easily made across the different synthetic world sessions and concerning different participants. The annotated data and analyses presented in this paper are available in an open-access distinguished LETEC corpus (Wigham, 2013).

\section{Data coverage}

Our study concerns data from three FLL and three EFL Second Life reflective sessions. The total data comprise 836 audio acts and 487 text chat acts. The total number of words (tokens) in these acts was 23,338. Appendix A shows a detailed breakdown of the data by group, session and actor.

\section{Interactions between text chat and audio modalities for L2 communication}

In this section, in consideration of the multimodal nature of synthetic worlds, we examine whether the text chat was used alongside or in adjunct to the voice chat and the discourse function of text chat acts.

\section{In synthetic worlds' multimodal context, to what extent is the text chat used for L2 communication?}

Our analysis shows a difference exists in the number of voice chat acts (aud) compared to the number of acts made using the text-based chat modality (tc) depending on whether the students had French or English as their L2. For the two EFL groups, a total of 450 audio acts are taken, compared to 386 audio acts for the FFL participants. Whilst the two EFL groups (SC and ES) show a tendency to use as many text chat acts as audio acts (session SC-j3) if not more text chat acts than audio acts (sessions ES-j2), the two FFL groups (LS and AV) used considerably more audio acts than text chat acts (Figure 3 ). There also exists a marked difference in the average number of text chat acts per session: the EFL groups used an average of 141 text chat acts per session compared to 21 for the FFL groups. 


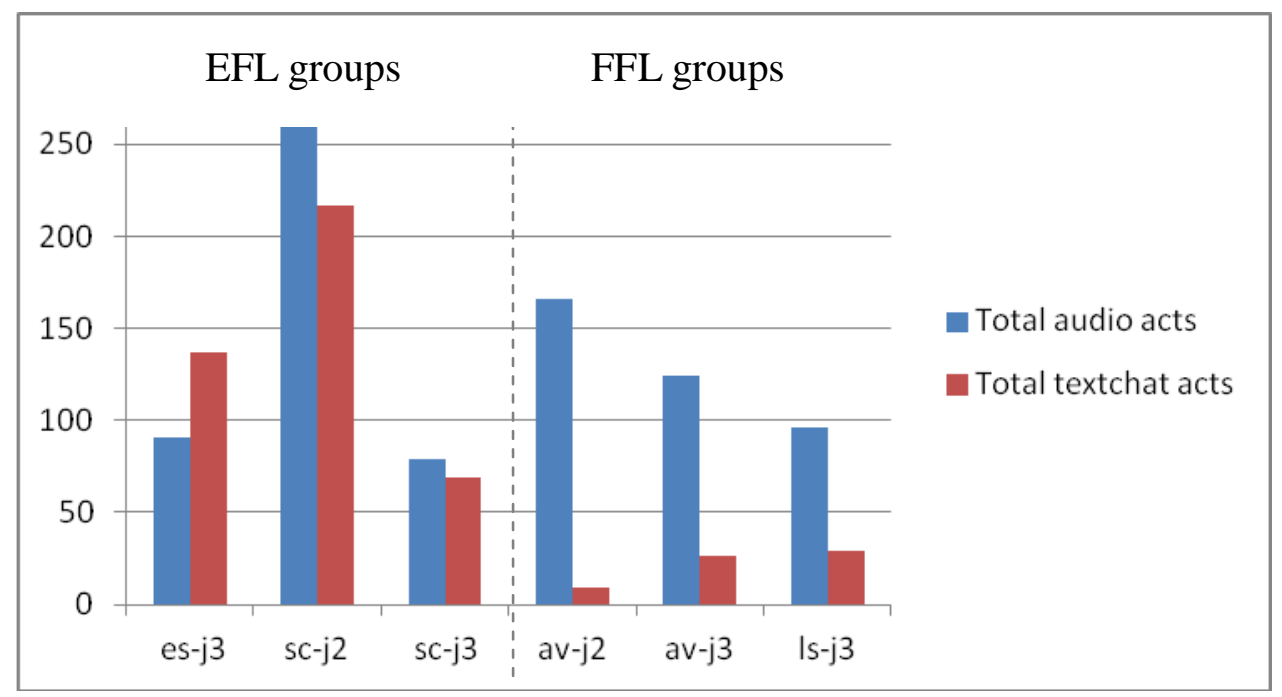

Figure 3. Distribution of audio and text chat acts during the sessions analysed

The total number of tokens in the audio acts did not differ considerably with respect to the participants' L2 (figure 4). However, the average number of tokens per audio act for a EFL group participant was lower (18.88 tokens / audio act) than that of a FFL group participant (28.81 tokens / audio act). In contrast, in any EFL session, an average of 724 tokens was used in the text chat, compared to an average of 52 tokens for the FFL sessions. An average act in the text chat for a participant in the EFL sessions contained 5.13 tokens, compared to 2.45 tokens in the FFL groups.

Our analysis shows that only in the EFL groups the text chat appears to have a place alongside the voice chat for L2 communication.

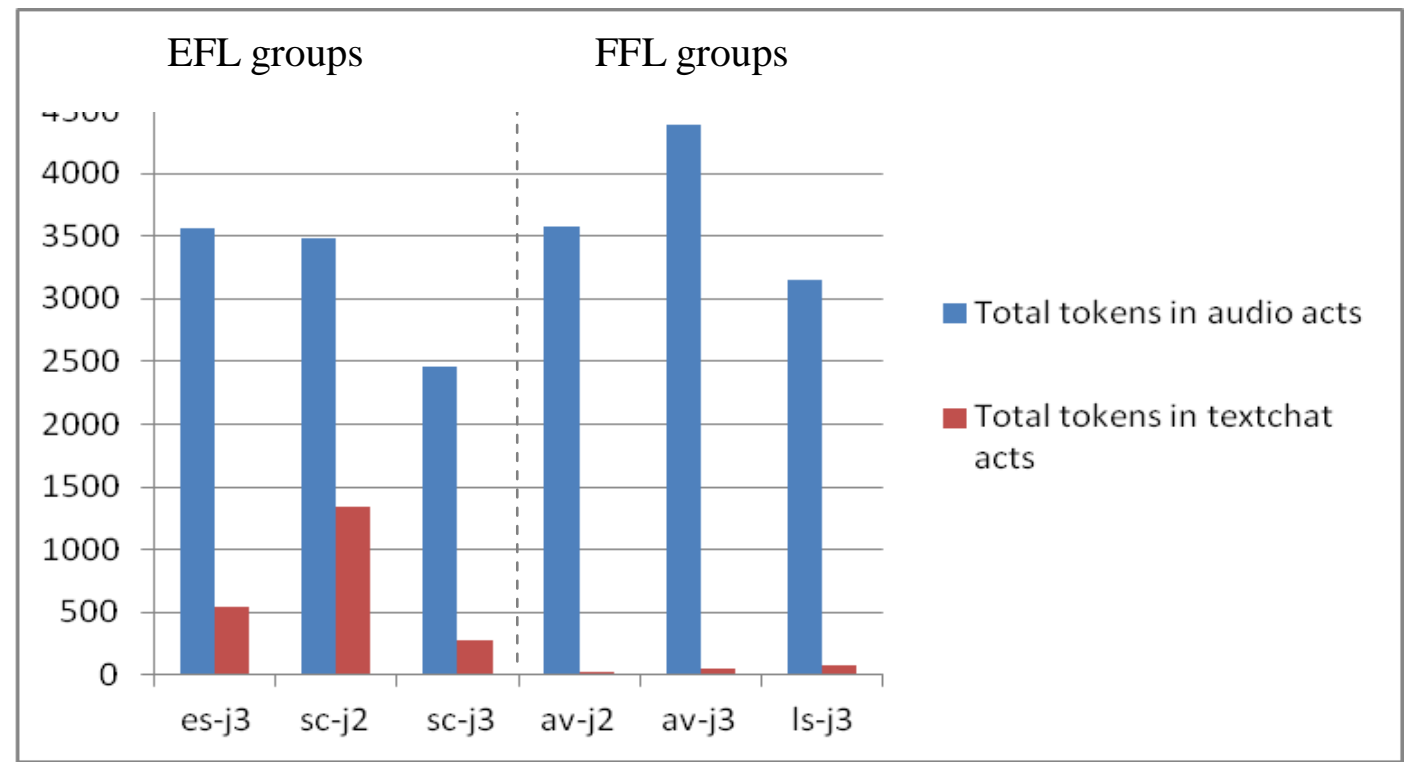

Figure 4. Distribution of tokens during sessions analysed

\section{EFL and FFL groups' differing usage of the text chat}

We have detailed the difference in quantity of text chat usage between EFL and FFL sessions. In this section, we examine text chat floor space balance between the students and tutor for each session, to analyse whether this may account for the quantitative differences in text chat uses between the groups. 
In the EFL sessions, the text chat modality took on an important role, being used frequently by both the students and the tutor within the interaction (Figure 5). The tutor, however, in all three EFL sessions occupied the most floor space in the text chat modality. In the FFL sessions, the text chat was much less frequently used and although in session AV-j2 floor space was equally distributed between tutor and students, in sessions AV-j3 and LS-j3 the text chat floor space was student-dominated.

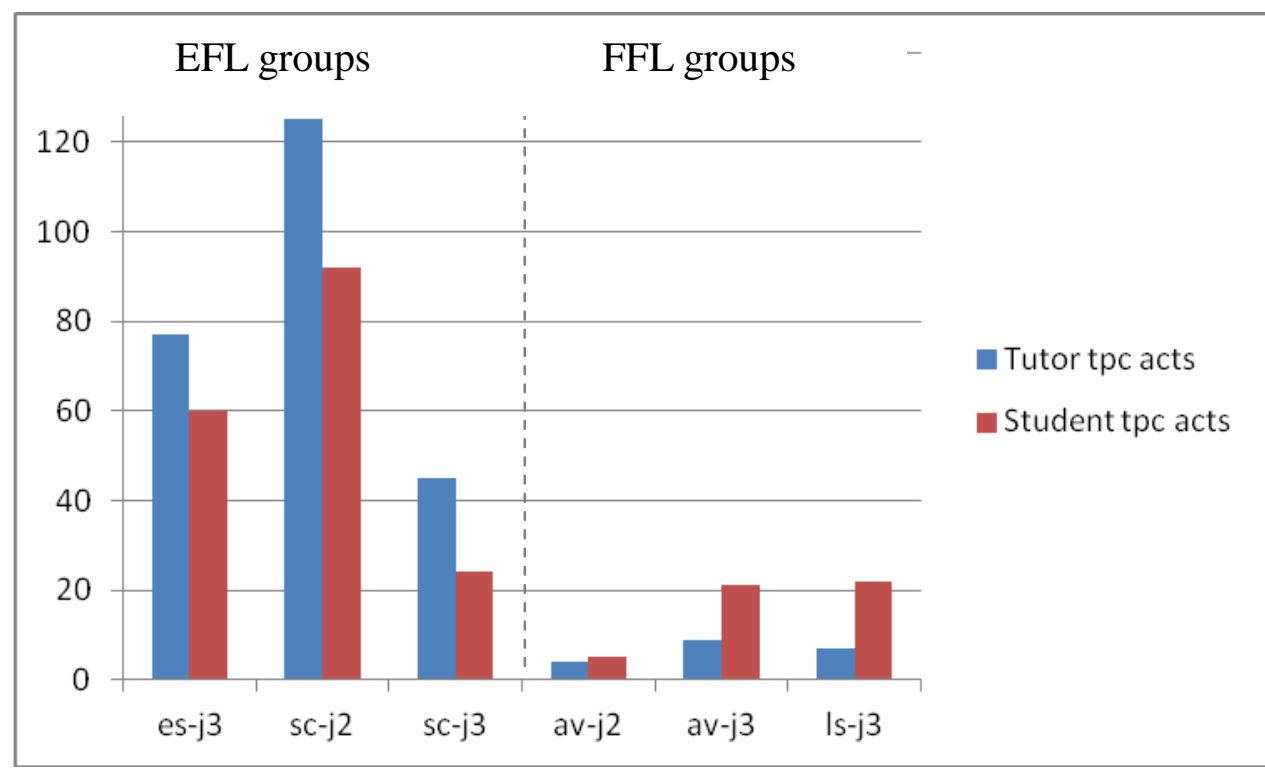

Figure 5. Division of text chat floor space between tutor and students for each session

The EFL tutor, who systematically used the text chat throughout the sessions showed the importance she placed on this modality to the students who, in turn, followed her lead and contributed regularly to the interaction in the text chat. Although the students contribute frequently in the text chat, as in Hampel \& Stickler's (2012) study, the EFL tutor remains the dominant participant in this modality. Contributing in both verbal modalities did not overload learners, however. The EFL students still make a substantial number of audio acts, in particular during session SC-j2 (figure 3). This suggests that the students did not find it difficult to manage both modalities simultaneously. Student comments in the post-questionnaires and interviews also highlight the interest students attributed to the verbal bi-modality of the environment, particularly for discussions of a collaborative nature (Wigham \& Chanier, 2013b).

In contrast, during the FFL sessions, the tutor, through adopting the voice chat primarily and the text chat infrequently, suggested that the latter modality was not central to the interaction within the sessions. This may be caused by a fear of overloading the learners considering the numerous modalities available for interaction (Table 2). The students, thus, followed her behaviour. They used the text chat infrequently, despite the fact that they occupied more text chat floor space, suggesting that they would have been keen to use this modality. 


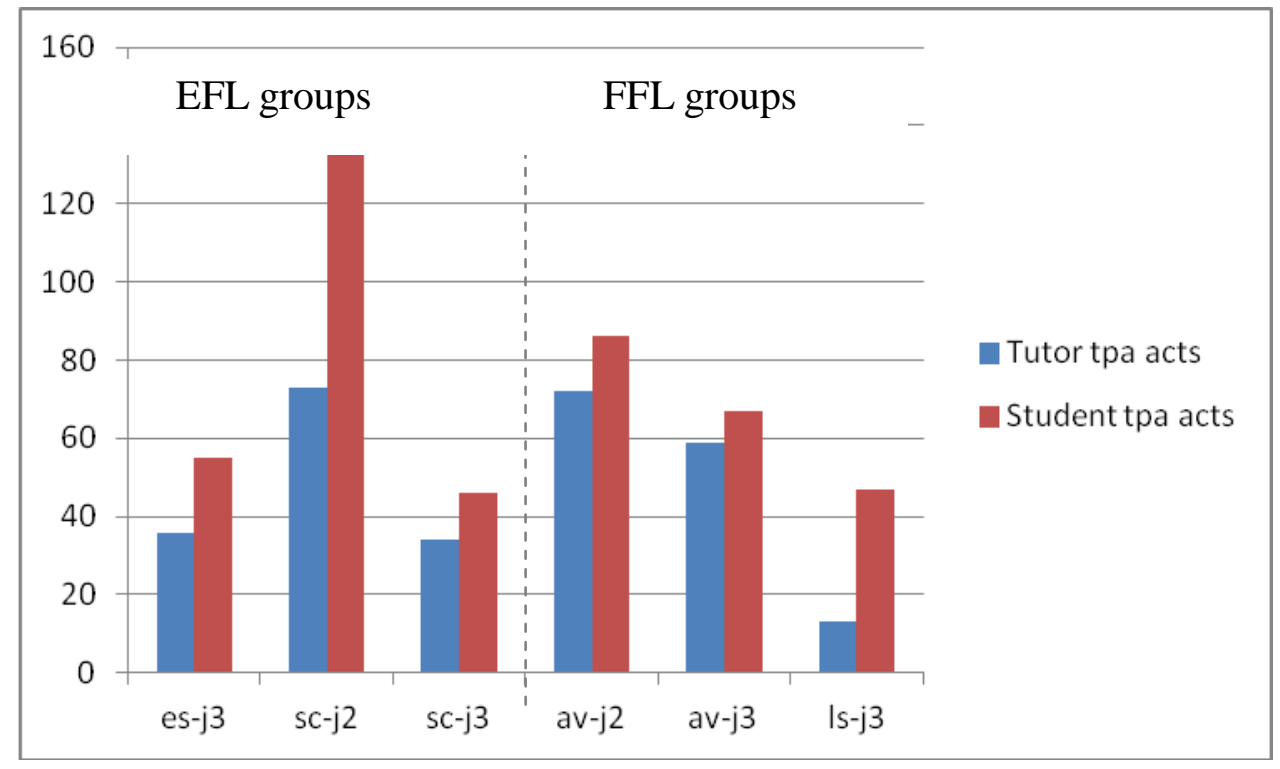

Figure 6. Division of audio floor space between tutor and students for each session

Did the FFL tutor favour the voice chat over the text chat because she preferred to control the interaction? When we look at the division of audio floor space between the tutor and students (Figure 6) we note that the FFL tutor only made one more act in the voice chat over the three sessions than the EFL tutor.Moreover, the students-tutor floor space proportions were similar: the EFL tutor's audio acts represented $38 \%$ of the floor space across the sessions whilst the FFL tutor's audio acts represented $36 \%$. Therefore, the FFL tutor's infrequent use of the text chat does not appear to be related to a preference for the voice chat in order to control the interactions.

As Blake (2005) and Hampel \& Stickler (2012) suggest, it appears necessary to raise L2 teachers' awareness concerning text chat usage, including the strategies needed to successfully combine voice chat and text chat when teaching in multimodal environments: the students appear keen to use both modalities but are potentially impeded from doing so by the tutor's consideration of the text chat as peripheral to the verbal interaction.

\section{Function of the text chat}

The EFL groups' data show that the text chat has a place within multimodal communication in synthetic worlds. We now turn to examine its role and whether it is used simply for managing technical problems, in the opening and closing of sessions or for off-task asides as suggested in previous literature, or whether it plays a more central role in the L2 communication.

Our analysis of the role of the text chat acts for both the EFL and FFL sessions shows that they were not simply of a technical order (Figure 7). Acts referring to technical issues in the synthetic world represented between 3 and $28 \%$ of all text chat acts for the six sessions analysed. 


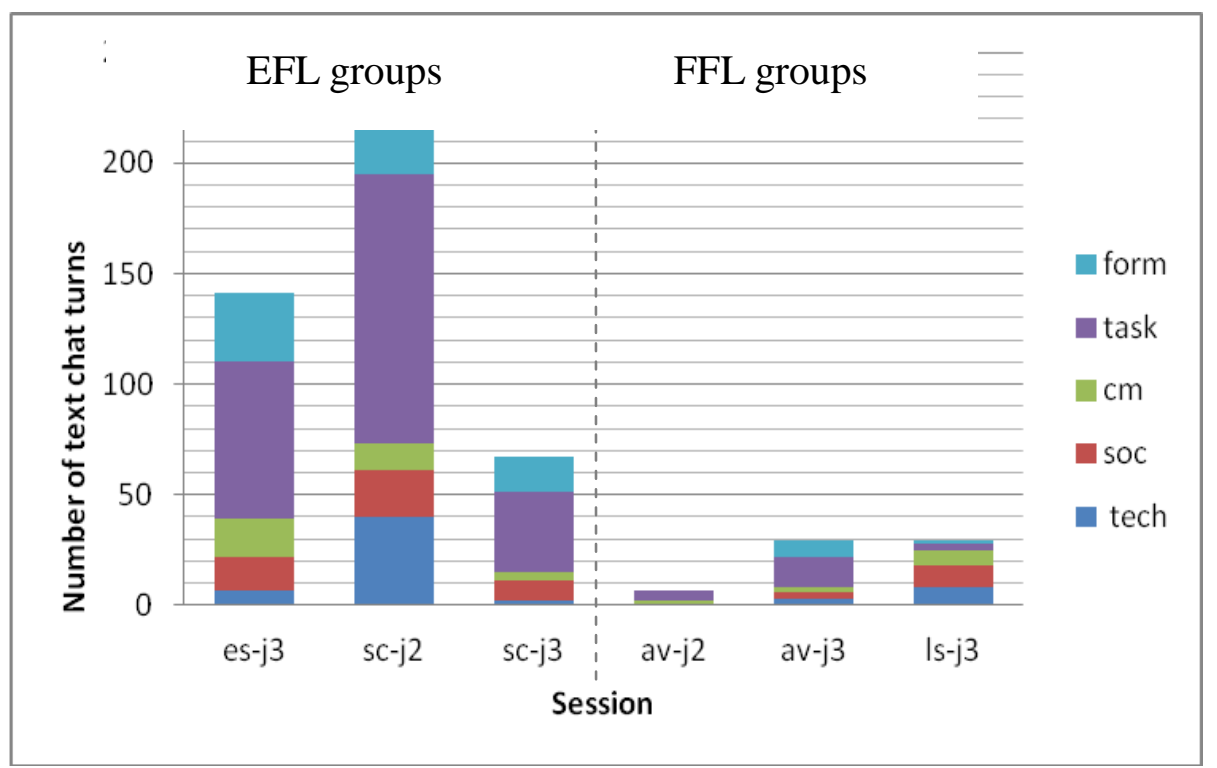

Figure 7. Function of text chat acts

In five of the six sessions, between $48 \%$ and $71 \%$ of text chat acts were used with reference to the task at hand. This said, the total number of acts used with reference to the task was considerably more important in terms of absolute figures for the EFL groups, ranging from 36 acts in session SC-j3 to 122 acts in session SC-j2, in comparison to a maximum of 14 acts concerning the task (session AV-j2) during the FFL sessions.

In session SC-j2, 20 text chat acts concerned form compared to 16 in $\mathrm{SC}-\mathrm{j} 3$ and 31 in ES-j3. For the FFL sessions these numbers are significantly smaller: In session one text chat act in LS-j3, two in AV-j2, and seven in AV-j3. Focusing on the tutor's use of the text chat, the majority of the EFL tutor's text chat acts (between $54 \%$ and $59 \%$ of all text chat acts per session) concern the task. An average of $22 \%$ of her text chat acts (an average of 16 acts per session) refer to language form.

It appears that the text chat modality also allowed the EFL tutor to address a central problem within language teaching of whether to give greater value to communicative meaning, which is paramount, or to comprehensible form, without which linguistic competence cannot be fully obtained. The multimodality allowed the tutor to pay attention both to problems of meaning of students' utterances without this being to the detriment of form and vice-versa.

\section{Feedback}

We turn, now, to look more specifically at the role the text chat played in feedback provision. In this section of our analysis, we consider only the EFL groups, for whom the use of the text chat modality was frequent. Such small raw numbers of text chat acts concerning form in the FFL sessions will not allow us to draw any reliable conclusions. We examine the question of whether the characteristics of the feedback offered concerning language form in the text chat modality resemble those of previous studies into monomodal environments and whether feedback leads to modified output and in which modality responses to feedback are given. 


\section{Feedback on what type of error? Is feedback predominantly lexical?}

In two of the three EFL sessions analysed, the majority of error triggers pertained to lexical non-target-like (NTL) forms (Table 4). In sessions ES-j3 and SC-j3, there was greater variety of NTL forms which received feedback, including corrective feedback being given on idiomatic NTL forms and typological NTL forms.

\begin{tabular}{|c|c|c|c|c|c|c|}
\hline \multirow{2}{*}{ Session } & \multicolumn{5}{|c|}{ Type of NTL form receiving corrective feedback } \\
\cline { 2 - 7 } & $\begin{array}{c}\text { Typologic } \\
\text { al }\end{array}$ & Lexical & $\begin{array}{c}\text { Gramm } \\
\text { atical }\end{array}$ & Pragmatic & Idiomatic & $\begin{array}{c}\text { Pronunciatio } \\
\mathbf{n}\end{array}$ \\
\hline SC-j2 & 0 & 13 & 3 & 0 & 0 & 0 \\
\hline SC-j3 & 1 & 5 & 7 & 0 & 3 & 0 \\
\hline ES-j3 & 1 & 13 & 12 & 0 & 3 & 0 \\
\hline
\end{tabular}

Table 4. Types of non-target-like forms receiving corrective feedback shown per session

These results align with previous studies of feedback in monomodal environments. Similar to Tudini's (2007) study, grammatical feedback receives attention but correction on lexical NTL forms is dominant as reported by Blake (2000), Pellettieri (2003) and Tudini (2003). However, whilst Tudini (2007) reports that the NSs intervened more frequently concerning grammatical rather than lexical NTL forms, the interventions of the NS tutors in our study show the contrary. This may be due to the nature of the task-type: lexical NTL forms may lead to greater communicative breakdown in an open-discussion than grammatical NTL forms and thus are given greater importance by the tutor.

\section{What type of feedback is offered?}

In this section, we analyse the type of feedback offered in the text chat according to the categorisation of forms feedback might take adopted in our annotation methodology (see Figure 3).

Three occurrences of student self-correction and three occurrences of peer correction were found. The remaining 43 occurrences of feedback were offered by the tutor. $17 \%$ of the tutor's text chat acts contained corrective feedback on the students' audio productions. Recasts were the predominant feedback type (32 instances, Figure 8) alongside reinforcement (10 instances) which frequently occurred following self-correction in the voice chat. Other types of feedback were used infrequently (either two or three instances of other feedback types). No occurrences of repetition of erroneous output or instances of comprehension checks were found. 


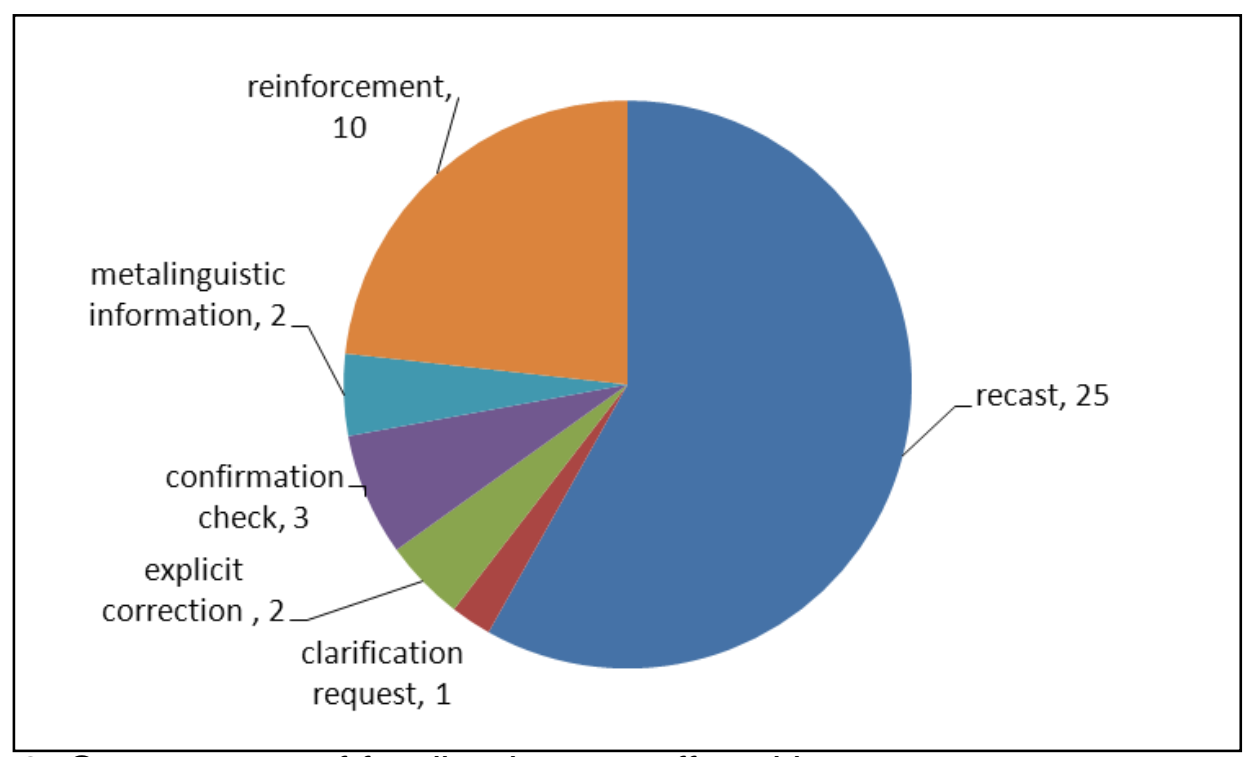

Figure 8. Occurrences of feedback types offered by tutor

With respect to the rate of feedback offered, our results for tutor feedback are slightly lower than in previous studies (Lee, 2006; Sotillo, 2005). This may be due to the task which was not uniquely language focused. The tutor, in the open-discussion, had to help the group advance with respect to their macro task of building a model in response to a design brief. Greater importance may therefore have been accorded to communication concerning the group task rather than correct linguistic form. This may also explain predominant use of recasts: it appears the tutor does not want to interrupt the discussion and choses to provide the correct language form directly rather than deflect the discussion of the macro task into a purely linguistic discussion.

Considering that in the language learning sessions, because of the nature of the learning, the audio modality takes precedence, if the message of the audio production is not comprehensible, it would appear natural for the language tutor to intervene in this modality to resolve this. This is particularly because the audio in the synthetic world is fully duplex: the tutor does not have to wait her turn before intervening and, therefore, can address comprehension breakdowns directly. This may explain the lack of comprehension checks in the text chat modality.

\section{Do students respond to feedback? When does this occur and in which modality?}

Previous studies of monomodal text chat environments show a varying rate at which the non-target-like acts receiving corrective feedback led to modified output, percentages ranging from 25-60\% (see Iwasaki \& Oliver, 2003; Lee, 2006; Sotillo, 2005). Given the highly multimodal nature of synthetic worlds, which may overload learners, in this section we examine whether learners are able to respond to the feedback offered and if so, how they do so.

Of the 43 occurrences of corrective feedback offered to the students by the EFL tutor in the text chat, 25 instances were responded to (Figure 9). Hence, $58 \%$ of all corrective feedback was responded to by students either by the students' repeating the correct form, including the correction in their 
interaction (whether correctly or incorrectly), or by students' acknowledging the tutor's correction.

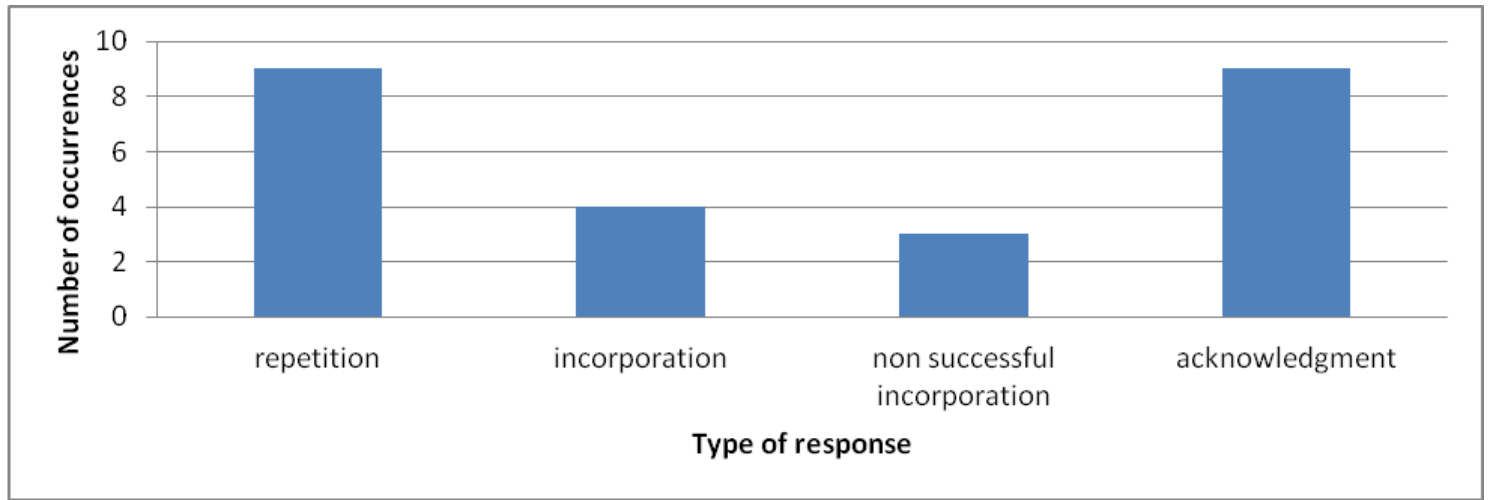

Figure 9. Students' responses to the EFL tutor's feedback

Of the 25 occurrences of corrective feedback made in text chat acts that were responded to, 20 were responded to in audio acts and five in text chat acts. Example 2 illustrates corrections in the text chat modality being responded to in the audio modality. The student Tingrabu continues his audio act whilst the tutor Tfrez2 corrects his grammatical errors in the text chat. The student then incorporates the correction into his audio act and also acknowledges the correction by apologising for his mistake (anno= id="an21").

(2) aud, tingrabu [07:20-08:48]: ok $\mathrm{hm}$ for me this presentation was $\mathrm{hm}+$ become <anno id="an 18 ">too fast $</$ anno $>$ bccausc it's always the same in our architccturc school euh we have not time and $\mathrm{hm}+<$ anno id="an $21^{\text {" function }=" \text { form" }}$ $\mathrm{ntl}=$ "gram" type $=$ "cf-rpt ack" ref $="$ an $19 ">$ too quickly sorry $</$ anno $>$ and ...

tc, $<$ form $>$ tfrez2, [07:32-07:33]: <anno id="an 19" function="form" ntl="gram" type $=$ "cf--con" author="tut" ref="an 18 ">it went too quickly?</anno>

The majority of responses to feedback (16 out of 29) occur in the verbal act which followed the act in which the corrective feedback is given. There were five instances of corrective feedback being incorporated in the same audio act as that being corrected (Figure 10), as seen in Example 2.

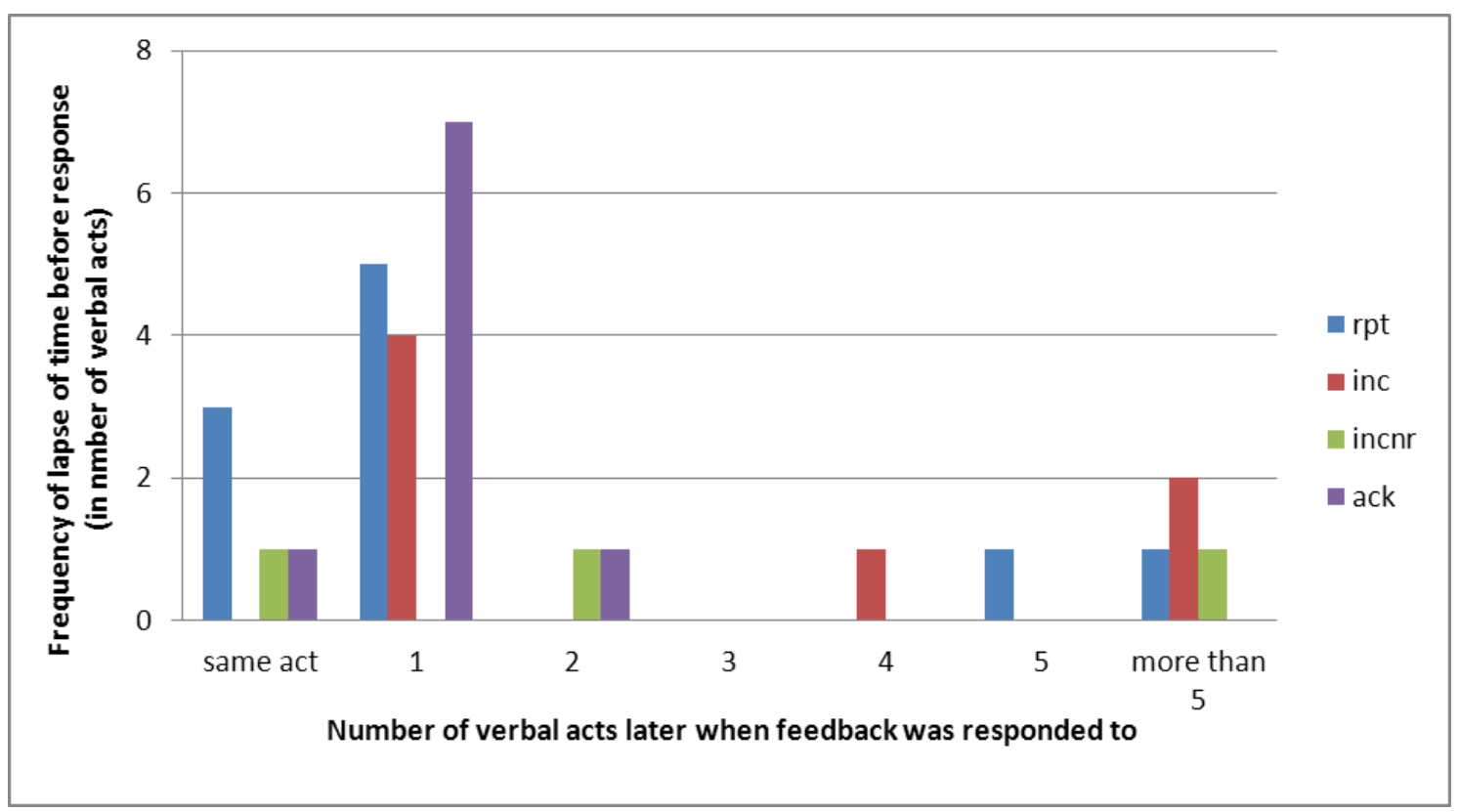


Figure 10. Time lapse (in number of verbal acts) before corrective feedback was responded to by students

Some corrective feedback was responded to later within the interaction. Fourteen per cent of corrective feedback was responded to over five verbal acts later in the interaction. Some of these responses were made by students other than those who produced the non-target-like trigger prompting the corrective feedback.

\section{Example of audio-text chat conversation doubling}

Following corrective feedback offered by the tutor, our data show instances of conversation doubling. These instances show participants' abilities to work simultaneously with different verbal modalities. Here we illustrate one example, for which the annotated transcription is found in Appendix B and illustrated in Figure 11.

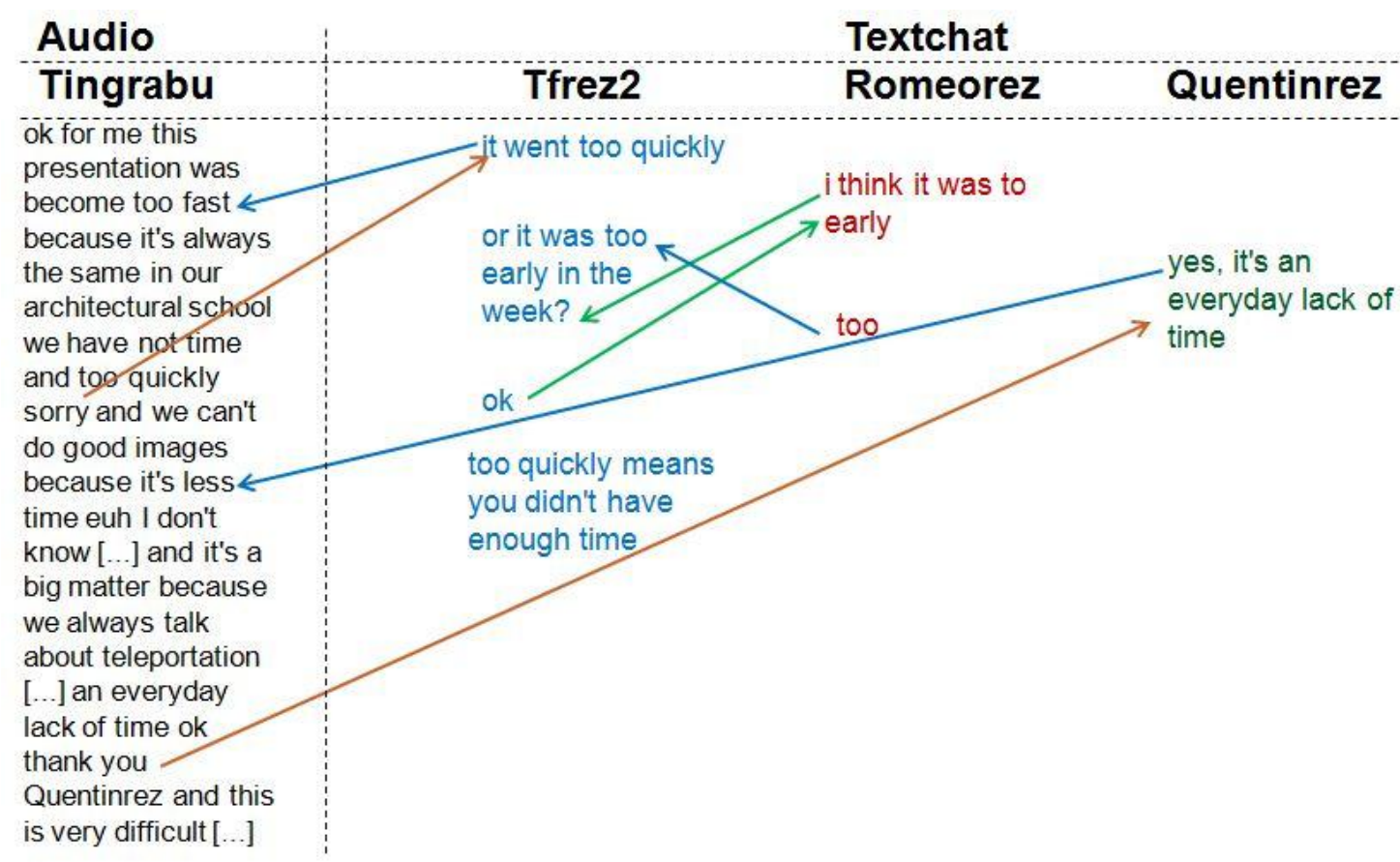

Figure 11. Example of conversation doubling

The student Tingrabu makes a grammatical error in an audio act. The tutor offers the student a split act confirmation check in the text chat. This correction is replied to by both the student to whom we can assume it was primarily addressed, Tingrabu, in the audio modality, and by Romeorez in the text chat modality. Tingrabu, in the continuation of his audio act, acknowledges the correction pertaining to language form by repeating the correction and apologising: the student is following the text chat as he uses the audio modality. Romeorez also replies to the corrective feedback in the text chat: he offers his personal opinion on the contents of the feedback which pertains to the task: "i think it was to early". The student then self-corrects his typographical error and the tutor similarly corrects this using the text chat. In this example, the input in the text chat led to interaction in the voice chat and the text chat modalities. However, the text chat also responds to both text chat and voice chat modalities. Later, in a text chat act, the student Quentinrez replies to the contents of his peer Tingrabu's audio act in a text chat act "you didn't have 
enough time". The tutor then offers corrective feedback in the text chat on both the error made in the student Tingrabu's audio act and in Quentinrez's text chat act (an31).

In this example of conversation doubling, the acts in the text chat respond to the voice chat (Figure 11, blue arrows) but equally acts in the voice chat respond to the text chat (orange arrows) and, as described above, text chat acts respond to interaction in both voice chat and text chat modalities and prompt interaction in both modalities.

\section{Uptake of feedback}

Our study shows that there is uptake of feedback with $58 \%$ receiving a response. We consider 'uptake', with reference to Lyster \& Ranta (1997), as a student reaction to a tutor's feedback that draws attention to an aspect of the student's initial production. Unlike in other studies where corrective feedback leads to high rates of modified output (see Iwasaki \& Oliver, 2003; Lee, 2006; Sotillo, 2005), our data shows that incorporation of the feedback within an utterance in the target-like form represented only $9 \%$ of responses: student acknowledgement or repetition of the feedback was more common. This may be explained by students giving greater importance to the architectural macro task than to correct linguistic form. It does not suggest that the students were cognitively overloaded: the high rate of feedback being responded to in general (by repetition, correction (or not), incorporation and acknowledgement) shows that the students are aware of the multimodality of the environment (see also Wigham \& Chanier, 2013b). Indeed, they monitor the text chat whilst speaking and incorporate text chat comments into productions in the audio modality. The teacher similarly monitors both modalities as she offers feedback on both the audio acts and text chat acts.

Kitade (2000) observed that self-repair was facilitated by text chat tools which allow learners to scroll back to monitor their language production. Our study further suggests that in a multimodal environment, because the text chat modality remains available for all students to view, this helps the students who produced non-target-like forms and their peers to incorporate feedback several acts later within the interaction. The text chat remains as a reminder of the correct target-like form.

Our analysis reinforces the suggestion (Vetter \& Chanier, 2006) that the idea of 'adjacent pairs' needs to be reconsidered and reinterpreted in a multimodal context. The majority of students responded to feedback that occurred in the verbal act which was adjacent to the text chat act in which the corrective feedback was given. Furthermore, the tutor's contributions in the text chat responded to contributions in both verbal modalities and also prompted immediate reactions in different modalities.

\section{Conclusions and perspectives}

This paper described the interplay between the audio and text chat modalities during six CLIL sessions held in the highly multimodal synthetic world Second Life. With respect to our first research question concerning the role played by the text chat modality in the interaction, this study revealed that text chat usage was influenced by the tutors' attitudes towards this modality. The tutor who systematically used the text chat showed the importance she placed on this 
modality within the interaction, and the students followed this lead by contributing regularly in the text chat. The tutor who primarily adopted the voice chat, however, showed that the text chat was not central to interaction and, while the students showed an eagerness to use the modality, the interaction took place in the audio modality.

The text chat was used for content-based interaction concerning the task. It also supported the audio modality by enabling the tutor to address problems of nontarget-like forms in students' verbal productions unobtrusively without this impeding the advancement of the task and without interrupting their interaction. These findings contrast with other studies into the role of the text chat in multimodal environments as discussed in Section 1, including Palomeque's (2011) study related to synthetic worlds, where the text chat is perceived as having a secondary role dedicated to social or technical issues.

Regarding our second research question, the study showed that the text chat served for feedback on non-target-like errors in the audio modality. Students' high response rate to this feedback illustrates they were able to manage both modalities simultaneously, monitoring the text chat whilst contributing in the audio modality. Responses to text chat feedback most frequently occurred in the act following that in which the feedback was provided. The responses were largely cross-modal: the majority of responses to feedback were in the audio modality rather than the text chat modality in which the feedback was provided. It thus appears that the combination of using the audio and text chat modalities simultaneously did not present a cognitive overload for the students. This may go some way to reassuring language tutors about overloading learners if both modalities are used in the synthetic world (cf. Deutschmann \& Panichi, 2009).

The feedback provided in the text chat was predominantly in the form of recasts responding to lexical non-target-like triggers. This finding agrees with studies concerning feedback in monomodal text chat environments (Blake, 2000; Pellettieri, 2003; Smith, 2003; Tudini, 2003) that also draw attention to a focus on lexical rather than grammatical non-target-like language in corrective feedback.

Our study's findings highlight several pedagogical implications. Firstly, that we need to provide teachers who wish to teach in synthetic worlds or other environments that combine audio and text chat modalities with the strategies needed to use bi-verbal modalities. Our study examined whether the recommendations highlighted in previous studies of simple multimodal environments were equally true of synthetic worlds in which, through their avatar, users have to manage the non verbal communication mode in addition to the audio and verbal modalities. Whilst studies into simpler multimodal environments recommend the need, in general, to train teachers in how to exploit bi-verbal modalities, our study highlights a specific training - that of training teachers in strategies to provide feedback in the text chat.

Secondly, this study suggests that a potential way to correct language form without interrupting communication would be to use CMC environments which are bi-modal in the verbal mode and include both voice chat and text chat modalities. This was studied in sessions concerning an open discussion task in which the tutors' role was to encourage the discussion and help the group advance in their response to the design brief, despite the domain of architecture 
not being an area of expertise for the language tutors. The EFL tutor may have adopted a strategy of using the text chat modality for acts concerning the task because it allowed her to reduce the cognitive load. Her use of the text chat modality, where the task was concerned, also allowed her to contribute to the session and to manage the advancement of the group without taking too big a risk of losing face.

The situation of teachers' non-expertise regarding the task is common in taskbased language learning (e.g. Vetter \& Chanier, 2006). Further studies concerning how teachers can support language learning whilst managing non linguistic task advancement in multimodal CMC environments are needed.

Although Second Life is one of the more popular social synthetic worlds for educational uses, a possibility in CALL research would be to investigate other synthetic worlds where text and audio modalities may be supported slightly differently. For example, in the social synthetic world Active Worlds text chat acts are displayed simultaneously in the chat window and in speech bubbles above avatars' heads. The increased saliency lent to the text chat by these features may increase participants' responses to text chat acts. Exploring the interactions between voice chat and text chat may not only yield implications for the design of these environments but also contribute to our understanding of the role of the text chat in multimodal interaction.

Finally, the intensive and time-limited nature of a workshop / studio learning situation where our experiment took place does not allow for language acquisition to be measured. Further research that is longitudinal in nature is clearly needed to investigate the impact of the multimodal nature of synthetic worlds on second language acquisition.

\section{Acknowledgements}

The authors wish to thank Paul Lotin for designing the programme Comptage which was used to count our XML annotations, Inès Saddour for her contributions to the processes of data transcription and corpus constitution, Susan Davis for her proofreading skills and our anonymous reviewers for their feedback on earlier drafts.

\section{References}

Beißwenger, M. Ermakova, M., Geyken, A., Lemnitzer, L. \& Storrer, A. (2012). A TEI Schema for the Representation of Computer-mediated Communication, Journal of the Text Encoding Initiative, 3. doi : $10.4000 /$ jtei.476

Blake, R.J. (2000). Computer mediated communication: A window on L2 Spanish interlanguage. Language Learning and Technology, 4(1): 120136.

Blake, R.J. (2005). Bimodal CMC: The Glue of Language Learning at a Distance, CALICO Journal, 22(1): 497-511.

Bower, J. \& Kawaguchi, S. (2011). Negotiation of Meaning and Corrective Feedback in Japanese/English eTandem. Language Learning and Technology, 15(1): 41-71. 
Chanier, T. \& Wigham, C.R. (2011). (Eds.) Learning and Teaching Corpus (LETEC) of ARCHI21. Mulce.org : Clermont Université. [oai : mulce.org:mce-archi21-letec-all ; http://repository.mulce.org]

Chun, D. (1994). Using Computer Networks to Facilitate the Acquisition of Interactive Competence. System, 22(1): 17-31.

Ciekanski, M., \& Chanier, T. (2008) Developing online multimodal verbal communication to enhance the writing process in an audio-graphic conferencing environment. ReCALL, 20(2): 162-182. doi:10.1017/S0958344008000426

Cosnier, J. \& Develotte, C. (2011). Le face à face en ligne, approche éthologique, in Develotte, C., Kern, R. \& Lamy, M-N. (2011). Décrire la conversation en ligne. ENS Editions: Lyon.

Council of Europe (2003). Common Framework of Reference for Languages. Cambridge University Press: Cambridge.

Cunningham, U., Fâgersten, K. \& Holmstem, E. (2010). "Can you hear me, Hanoi?" Compensatory mechanisms employed in synchronous net-based English language learning, International Review of Research in Open and Distance Learning, 11(1), pp.165-185.

Dalgarno, B. \& Lee, M.J.W. (2009). What are the learning affordances of 3-D virtual environments? British Journal of Educational Technology, 41(1): 10-32.

Deutschmann, M. \& Panichi, L. (2009). Instructional design, learner modelling, and teacher practice in Second Life. In J. Molka-Danielsen and M. Deutschmann. (Eds.) Learning and Teaching in the Virtual World of Second Life. Tapir Academic Press: Norway. pp. 27-44.

Deutschmann, M., Panichi, L., \& Molka-Danielson, J. (2009). Designing oral participation in Second Life - a comparative study of two language proficiency courses. ReCALL, 21(2): 206-226. doi:10.1017/S0958344009000196

Do, E. \& Gross, M.D. (1998). The Design Studio Approach: Learning Design in Architecture Education, In Kolodner, J. \& Guzdial, M. (Eds.) Design Education Workshop. Atlanta: Georgia Institute of Technology. [http://depts.washington.edu/dmgftp/publications/pdfs/edutech97-eyd.pdf].

Freiermuth, M. (2001). Native Speakers or Non-Native Speakers: Who Has the Floor? Online and Face-to-Face Interaction in Culturally Mixed Small Groups, Computer Assisted Language Learning, 14(2): 169-199.

Freiermuth, M. (2011). Debating in an online world: a comparative analysis of speaking, writing, and online chat, Text and Talk, 31(2): 127-151.

Freiermuth, M. \& Jarrell, D. (2006). Willingness to communicate: can online chat help ? International Journal of Applied Linguistics, 16(2) : 189-212.

Garner, S., Schadewitz, N., Holden, G., Zamenopoulos, T. \& Alexiou, K. (2011). Supporting Fragility in Distance Design Education, In T. Zupančič-Strojan, M. Juvančič, S.Verovše \& A. Jutraž (Eds.) (2011). Respecting Fragile Spaces: proceedings of the 29th Conference on Education in Computer 
Aided Architectural Design in Europe. Ljubljana: Faculty of Architecture. pp. 663-672.

Hampel, R. (2006). Rethinking task design for the digital age: A framework for language teaching and learning in a synchronous online environment, ReCALL, 18(1): 105-121. DOI: 10.1017/S0958344006000711

Hampel, R. \& Stickler, U. (2012). The use of videoconferencing to support multimodal interaction in an online language classroom. ReCALL, 24(2): 116-137. doi:10.1017/S095834401200002X

Iwasaki, J., \& Oliver, R. (2003). Chat-line interaction and negative feedback. Occasional Thematic Issue of the Australian Review of Applied Linguistics (ARAL), 17: 60-73.

Jauregi, K., Canto, S., de Graff, R., Koenraad, T. \& Moonen, M. (2011). Verbal interaction in Second Life: Towards a pedagogic framework for task design. Computer Assisted Language Learning, 24 (1): 77-101. doi:10.1080/09588221.2010.538699.

Kelm, O. (1992). The use of synchronous computer networks in second language instruction: A preliminary report, Foreign Language Annals, 25: 441-454.

Kern, R. (1995). Restructuring classroom interaction with networked computers: Effects on quantity and characteristics of language production, The Modern Language Journal, 79: 457-476.

Kitade, K. (2000). L2 Learners' discourse and SLA theories in CMC: Collaborative interaction in Internet chat. Computer Assisted Language Learning, 13 (2): 143-166. doi: 10.1076/0958-8221(200004)

Hoffman, R. (1996). Computer networks: Webs of communication for language teaching, In M. Pennington (Ed.) (1996). The power of CALL. Houston: Athelstan. pp. 55-78.

Lamy, M-N. \& Hampel, R. (2007). Online Communication in Language Learning and Teaching. Basingstoke: Palgrave Macmillan.

Lee, L. (2006). A study of native and non-native speakers' feedback and responses in Spanish-American networked collaborative interaction. In J. Belz\& S. Thorne (Eds.), Internet-mediated intercultural foreign language education. Boston: Thomson Heinle. Pp. 147-176.

Liddicoat, A.J. (2011). Enacting participation; hybrid modalities in online video conversation, in Develotte, C. Kern, R. \& Lamy, M-N. (Eds.) Décrire la conversation en ligne. Lyon: ENS Editions.

Liou, H-C. (2012). The roles of Second Life in a college computer-assisted language learning (CALL) course in Taiwan, ROC. Computer Assisted Language Learning, 25(4) :365-382.

Lyster, R. \& Ranta, L. (1997). Corrective feedback and learner uptake: Negotiation of form in communicative classrooms. Studies in Second Language Acquisition, 19 : 37-66. 
Morris, F. (2005). Child-to-child interaction and corrective feedback in a computer mediated L2 class, Language Learning and Technology, 9(1) :29-45.

O'Rourke, B. (2005). Form-focused interaction in online tandem learning. CALICO Journal, 22(3): 433-466.

Ortega, L. (1997). Processes and outcomes in networked classroom interaction: Defining the research agenda for L2 computer-assisted classroom discussion. Language Learning \& Technology (LLT), 1(1): 82-93.

Palomeque, C. (2011). Interaction and language learning in 3D virtual worlds. Communication at European Computer Assisted Language Learning Conference 2011, 31 August - 3 September, 2011, Nottingham: United Kingdom.

Payne, S. \& Whitney, P. (2002). Developing L2 oral proficiency through synchronous CMC: output, working memory and interlanguage development, CALICO, 20(1): 7-32.

Pearson Longman (nd.) Teacher's Guide to the Common European Framework. Pearson Longman. [http://www.pearsonlongman.com/ae/cef/cefguide.pdf]

Pellettieri, J. (2000). Negotiation in cyberspace: The role of chatting in the development of grammatical competence, in Warschauer, M. \& Kern, R. (Eds), Network-based Language Teaching: Concepts and Practice. Cambridge: Cambridge University Press.

Peterson, M. (2006). Learner interaction management in an avatar and chatbased virtual world. Computer Assisted Language Learning, 19(1):79103.doi: $10.1080 / 09588220600804087$

Peterson, M. (2010). Learner participation patterns and strategy use in Second Life: An exploratory case study. ReCALL, 22 (3): 273-292. doi:10.1017/S0958344010000169

Perkins, D. (2012), Studio Teaching in the Geosciences, [http://serc.carleton.edu/introgeo/studio/index.html]

Reffay, C. Betbeder, M-L. \& Chanier, T. (2012). Multimodal learning and teaching corpora exchange: lessons learned in five years by the Mulce project. International Journal of Technology Enhanced Learning (IJTEL), 4(12): 11-30.

Rodrigues, C., Wigham, C.R., Foucher A-L., \& Chanier, T. (in print). Architectural design and language learning in Second Life, in Gregory, S., Lee M.J.W., Dalgarno, B. \& Tynan, B. (Eds.) Virtual Worlds in Online and Distance Education. Edmonton: Athabasca University Press.

Sanchez, B. (1996). MOOving to a new frontier in language teaching. In M. Warschauer (Ed.), Telecollaboration in foreign language learning. Second Language Teaching and Curriculum Center, University of Hawai'i : Honolou. pp.145-164.

Smith, B. (2003).Computer-Mediated Negotiated Interaction: An Expanded Model. The Modern Language Journal, 87(1): 38-57. 
Sotillo, S. (2005). Corrective feedback via Instant Messenger learning activities in NS-NNS and NNS-NNS Dyads, CALICO Journal, 22(3): 467-496.

Stockwell, G. (2007) A review of technology choice for teaching language skills and areas in the CALL literature. ReCALL, 19(2): 105-120. doi: $10.1017 /$ S0958344007000225

Teoh, J. (2007). Second Life, a simulation: barriers, benefits, and implications for teaching. Proceedings of the 7th Technology, Colleges \& Community (TCC) Worldwide online conference (pp. 116-125). Hawaii, USA: University of Hawaii. [http://etec.hawaii.edu/proceedings/2007/teoh.pdf]

Toyoda, E. \& Harrison, R. (2002). Categorization of text chat communication between learners and native speakers of Japanese. Language Learning \& Technology, 6 (1): 82-99.

Tudini, V. (2003). Using native speakers in chat. Language Learning and Technology, 7(3): 141-159.

Tudini, V. (2007). Negotiation and intercultural learning in Italian native speaker chat rooms. Modern Language Journal, 91(4): 577-601.

Vetter, A., Chanier, T. (2006). Supporting oral production for professional purpose, in synchronous communication with heterogeneous learners. ReCALL, 18(1): 5-23. doi:10.1017/S0958344006000218

Warschauer, M. (1996). Comparing face-to-face and electronic discussion in the second language classroom, CALICO Journal, 13: 7-25.

Wehner, A., Gump, A. \& Downey, S. (2011). The effects of Second Life on the motivation of undergraduate students learning a foreign language. Computer Assisted Language Learning, 24(3):277-289.

Werry, C. (1996). Linguistic and interactional features of Internet relay chat. In Herring, S. (Ed.), Computer-mediated communication: Linguistic, social, and cross-cultural perspectives. Amsterdam: J. Benjamins. pp.47-63.

Wigham, C.R. (2013). (Ed.) Distinguished Corpus: Interplay between text chat and audio modalities during the Second Life Reflective Sessions. Mulce.org: Clermont Université. [oai : mulce.org:mce-archi21-modalitytextchat ; http://repository.mulce.org]

Wigham, C.R. \& T. Chanier (2013). A study of verbal and nonverbal communication in Second Life - the ARCHI21 experience. ReCALL 25(1): 63-84. doi: $10.1017 / \mathrm{S} 0958344012000250$

Wigham, C.R. \& T. Chanier (2013b). Les mondes synthétiques : un terrain pour l'approche Emile dans l'enseignement supérieur? in Ollivier, C. \& Puren, L. (Eds.) Mutations technologiques, nouvelles pratiques sociales et didactiques des langues. Recherches et Applications 54: 77-93.

Yun, H. (2009). Echanges à distance entre apprenants de FLE : Etude des interactions synchrones en contexte academique. Unpublished PhD thesis. Université Paris 3 - Sorbonne Nouvelle. 
Appendix A: Data breakdown by session, participant and modality

\begin{tabular}{|c|c|c|c|c|c|}
\hline Session & Participant & $\begin{array}{l}\text { Total audio } \\
\text { acts }\end{array}$ & \begin{tabular}{|l|} 
Total \\
tokens in \\
audio acts
\end{tabular} & $\begin{array}{l}\text { Total text } \\
\text { chat acts }\end{array}$ & $\begin{array}{l}\text { Total } \\
\text { tokens in } \\
\text { text chat } \\
\text { acts } \\
\end{array}$ \\
\hline \multirow[t]{5}{*}{ es-j3 } & Hallorann & 9 & 341 & 8 & 13 \\
\hline & Quentinrez & 18 & 894 & 7 & 24 \\
\hline & Romeorez & 14 & 482 & 30 & 139 \\
\hline & \begin{tabular}{|l} 
Tingrabu \\
\end{tabular} & 14 & 350 & 15 & 48 \\
\hline & \begin{tabular}{|l|} 
Tfrez2 \\
\end{tabular} & 36 & 1492 & 77 & 323 \\
\hline $\begin{array}{l}\text { Totals for } \\
\text { the } \\
\text { session } \\
\text { es-j3 }\end{array}$ & & 91 & 3559 & 137 & 547 \\
\hline \multirow[t]{5}{*}{ sc-j2 } & Arnaudrez & 54 & 588 & 13 & 41 \\
\hline & Audrezyrez & 14 & 171 & 62 & 378 \\
\hline & Jessieboo & 37 & 546 & 9 & 18 \\
\hline & Nathanrez & 29 & 479 & 8 & 18 \\
\hline & \begin{tabular}{|l|} 
Tfrez2 \\
\end{tabular} & 146 & 1698 & 125 & 890 \\
\hline $\begin{array}{l}\text { Totals for } \\
\text { the } \\
\text { session } \\
\text { sc-j2 } \\
\end{array}$ & & 280 & 3482 & 217 & 1345 \\
\hline \multirow[t]{5}{*}{$s c-j 3$} & Arnaudrez & 19 & 324 & 2 & 4 \\
\hline & Audrezyrez & 11 & 338 & 10 & 42 \\
\hline & Jessieboo & 11 & 288 & 3 & 10 \\
\hline & \begin{tabular}{|l|} 
Nathanrez \\
\end{tabular} & 4 & 121 & 9 & 16 \\
\hline & \begin{tabular}{|l|} 
Tfrez2 \\
\end{tabular} & 34 & 1386 & 45 & 207 \\
\hline $\begin{array}{l}\text { Totals for } \\
\text { the } \\
\text { session } \\
\text { sc-i3 }\end{array}$ & & 79 & 2457 & 69 & 279 \\
\hline
\end{tabular}

Table A. EFL groups' verbal act breakdown by session and participant 


\begin{tabular}{|c|c|c|c|c|c|}
\hline Session & Participant & \begin{tabular}{|l|} 
Total \\
audio acts
\end{tabular} & \begin{tabular}{|l} 
Total \\
tokens in \\
audio acts
\end{tabular} & $\begin{array}{l}\text { Total text } \\
\text { chat acts }\end{array}$ & $\begin{array}{l}\text { Total } \\
\text { tokens in } \\
\text { text chat } \\
\text { acts }\end{array}$ \\
\hline \multirow{4}{*}{ av-j2 } & Emmegi88 & 15 & 389 & 2 & 7 \\
\hline & Pjgamez & 24 & 627 & 0 & 0 \\
\hline & Prevally & 33 & 674 & 3 & 3 \\
\hline & Tfrez1 & 72 & $\overline{1076}$ & 4 & 15 \\
\hline $\begin{array}{l}\text { Totals for } \\
\text { the } \\
\text { session } \\
\text { av-j2 } \\
\end{array}$ & & 166 & 3583 & 9 & 25 \\
\hline \multirow[t]{5}{*}{ av-j3 } & Crispis & 7 & 484 & $\overline{3}$ & 5 \\
\hline & Emmegi88 & 10 & $\overline{477}$ & $\overline{9}$ & 17 \\
\hline & \begin{tabular}{|l|} 
Pjgamez \\
\end{tabular} & 21 & 725 & 0 & 0 \\
\hline & Prevally & 27 & 1145 & 5 & 5 \\
\hline & Tfrez1 & 59 & 1562 & $\overline{9}$ & 23 \\
\hline $\begin{array}{l}\text { Totals for } \\
\text { the } \\
\text { session } \\
\text { av-j3 } \\
\end{array}$ & & 124 & 4393 & 26 & 50 \\
\hline \multirow[t]{6}{*}{ Is-j3 } & Antoniobri & 3 & 344 & 4 & 20 \\
\hline & Huasha & 12 & 487 & 3 & 3 \\
\hline & $\begin{array}{l}\text { Hyungyoonr } \\
\text { ez }\end{array}$ & 14 & 319 & 7 & 14 \\
\hline & Zeinarez & 8 & 565 & 7 & 15 \\
\hline & Yingrez610 & 12 & 341 & 1 & 1 \\
\hline & Tfrez1 & 47 & 1091 & 7 & 29 \\
\hline $\begin{array}{l}\text { Totals for } \\
\text { the } \\
\text { session Is- } \\
\text { j3 }\end{array}$ & & 96 & 3147 & 29 & 82 \\
\hline
\end{tabular}

Table B. FFL groups' verbal act breakdown by session and participant 


\section{Appendix B: Example of conversation doubling}

(3) aud, tingrabu [07:20-08:48]: $\mathrm{ok} \mathrm{hm}$ for me this presentation was $\mathrm{hm}+$ become <anno $\mathrm{id}=$ "an 18 ">too fast $</$ anno $>$ because it's always the same in our architecture school euh we have not time and $\mathrm{hm}+<$ anno id="an 21 " function="form" ntl="gram" type="cf-rpt cf-ack" $\mathrm{ref}=$ "an $19^{\prime \prime}>$ too quickly sorry $<$ anno $>$ and $\mathrm{hm}+$ we can't do good images because euh + euh it's xtime I don't know + and euh of course we whole project + is about motion and hm we make just some pictures $\mathrm{hm}$ statics pictures and hm it's + and it's it's a big matter because $\mathrm{hm}$ we always brought about teleportation our + motion is and $\mathrm{hm}+++$ and $<$ anno id="an $27 "$ function=" form" ntl="lex" type="rpt ack" ref="an 29 ">everyday lack of time ok thank you $</ a n n o>\mathrm{xxx}$ and $\mathrm{hm}$ this is + this is $\mathrm{hm}$ really difficult for us because $\mathrm{hm}<\mathrm{anno}$ id $="$ an $28^{\prime \prime}>$ we have not enough time $</$ ann $0>$ to do good presentation euh in + one night and I hope so tues wednesday could be better + it should be + may be I don't know <anno id=" an $32^{\text {" }}$ function="form" type $="$ ack" ref $=$ "an $31 ">$ [chuckles $]<$ anno $>$

tc, $<$ form > tfrez2, [07:32-07:33]: <annoid="an19" function="form" ntl="gram" type="cfcon" author="tut" ref="an18">it went too quickly? $</$ anno $>$

tc, $<$ form $>$ tfrez2, [07:38-07:38]: $<$ anno id="an $20^{\text {" function}=" t a s k " ~ t y p e ~}="$ cf-con" author="tut" ref="an 18 " $>$ or it was too early in the week? $</$ anno $>$

tc, $<$ task>romeorez [07:54-07:55]: $<$ anno id="an 22 "ref="an $20 ">i$ think it was to early $<$ anno $>$

tc, $<$ form $>$ romeorez [07:59-07:59]: $<$ anno id="an23" function=" form" ntl="typ" type="cf$\mathrm{sr}^{\prime}$ author="st" ref="an 22 ">too $</$ anno $>$

tc, $<$ form $>$ tfrez2 [07:59-07:59]: $<$ anno id="an 24 " function="form" ntl="gram" type="cf-rec" author="tut" ref="an 22 ">too early $<$ anno $>$ <anno id="an 25 " function="form" type="cf-ref" author="tut" ref="an 23 " $>$ ok $</ a n n o>$

tc, $<$ form $>$ tfrez2 [08:08-08:10]: $<$ anno id="an 26 " function=" form" ntl="gram" type="cf-ml" author="tut" ref="an 21 ">too quickly means that you didn't have enough time to speak $</$ anno $>$

tc, <task form >quentinrez [08:16-08:16]: <anno id="an29" type="cf-pr" author="pr"ref="an 28 ">yes, it's an everyday lack of time $<$ anno>

tc, $\angle$ task $>$ romeorez [08:43-08:43] : $<a n n o i d=" a n 30 " r e f="$ an $28 ">$ that more that we have to show something that we don't really know $</$ anno $>$

tc, $<$ form > tfrez2 [08:08-08:10]: <anno id="an 31" function="form" ntl="gram" type="cf-rec" author="tut" ref=" an 28 an 29 ">you didn't have enough time $</$ anno $>$

tc, $\langle$ task $>$ romeorez [08:43-08:44] : $<$ anno id $="$ an $27 "$ ref $="$ an $28 ">$ fore the shape $</$ anno $>$ 